\title{
Energy-Efficient Planning Tool for WCDMA Heterogeneous Network Deployment
}

\author{
${ }^{1}$ A. A. Ayeni, ${ }^{2}$ N. Faruk and ${ }^{3}$ K.A. Sadiq \\ ${ }^{1,2}$ Department of Telecommunication Science, University of Ilorin, Ilorin, Nigeria \\ ${ }^{3}$ Department of Computer Science, Kwara State Polytechnic, Ilorin, Nigeria
}

\begin{abstract}
The population of powerful mobile network technologies has increased in recent years also focus has been shifting from second generation mobile to third generation technology. This higher access rates have led to increased energy consumption in base stations (BTS) and network densities have been constantly growing. This paper developed an energy efficient planning tool for analytical modeling of heterogeneous networks and observed the potential energy savings statistics when deploying heterogeneous networks. A model developed from wcdma downlink equation was used in determining the energy consumption per unit area of the network. The model was also used to observe how heterogeneous network deployment contributes to the total energy consumption of the network. The result was presented in three scenarios. The first scenario presented the daily energy consumption per square kilometer and it was observed that the energy consumption by the macrocell decreases when increasing the ratio of femtocells in the network. However, the introduction of femtocells to the network ordinarily does not gauranty decrease in energy consumption the scenario depends on the power budget of the femtocells as presented in second and third scenarios where power budget of $2 \mathrm{~W}$ and $5 \mathrm{~W}$ were used respectively. By introducing femtocell of low power budget into the network, the density of the network reduces therefore, bringing about reasonable reduction in the total power consumption of the network. To that end, this research developed software that helps to observe the total energy that could be saved when deploying heterogeneous networks.
\end{abstract}

\section{Keywords}

Energy Efficiency, Femtocell, Load Sharing, Macrocell, Power Consumption

\section{INTRODUCTION}

Energy efficiency in mobile communication is becoming an important topic across the globe for the fact that information and communication technology is responsible for about $2-4 \%$ of the global carbon emission $[1,2]$. The trend in mobile communication today has approached new technologies like Wideband Code Division Multiple Access (WCDMA); Enhanced Date Rates for GSM Evolution (EDGE); Long Term Evolution (LTE) etc and all these technologies are known to provide users with high bit rates and they demand a high data transmission rate to provide these bit rates. In recent times, multimedia users or third generation network mobile network are tremendously growing and are responsible for the huge part of traffic on mobile access networks [3]. As the number of subscribers increase, the capacity need to increase and this require additional network resources like BTS in order to avoid traffic congestion in the network, solutions to reduce the energy consumption due to additional base stations needs to be considered because around $80 \%$ of the total network energy is consumed by the base stations [4][5].
Recently, most energy saving researches has been focused on the base stations because of the statistics mentioned earlier. Many strategies like improvement in base station energy efficiency through better performance of base station hardware, usage of system level and software features, usage of base station site solutions, heterogeneous network deployment etc has been proposed [4][6] but only heterogeneous network deployment was considered in this report. This paper focused on wcdma technology because from the report of the standardization forums, wcdma technology has emerged as the most widely adopted third generation air interface [7]. Also, it is easy to take advantage of the downlink load equations of wcdma, the link budget equations and energy consumption equations can all be easily tracked from available literatures. To that end, we developed a stand-alone energy efficient planner that performs network dimensioning automatically and gives out graphic results based on the results obtained. The work in [8] is an advanced radio planner integrated with features such as Google earth, mesh and point to multi point design, RF prediction etc. The work in [9] is a java based network planner that has the ability to accommodate infrastructure sharing of network. The works in $[8,9]$ can only analysis where the base stations could be sited for better performance where aspect of energy efficiency was not covered. This paper gives a clear insight on how load sharing between macrocell and femtocell (heterogeneous network deployment) contributes to the networks energy consumption. The rest of this paper is organized as follows: section 2 covers heterogeneous network deployment in BTS, section 3 discussed the system model while the power constraints was discussed in section 4 , section 5 and section 6 gives the numerical example and numerical results. The conclusion was stated in section 7 .

\section{HETEROGENEOUS NETWORK DEPLOYMENT}

Heterogeneous networks is an organized mixture of networks where high power budget macrocells are combined with many nodes usually low power nodes like picocell, distributed antennas, femtocells and relays. The low power nodes are mostly deployed to compensate for poor coverage experienced by some selected indoor and outdoor environments. The low power nodes are may also be deployed to relief the high power cells during off peak period in order to minimize the energy consumed by the network

\subsection{Macrocells}

Microcells provide radio coverage for cell in a mobile phone network. The radio coverage is transmitted with high power budget than other radio coverage cells like microcells. The antenna for macrocells could be installed on (ground mast, rooftop etc) at a height that can accommodate clear reception over the building surrounding it and also the geographic terrain should also be considered. The macrocells are known 
for about $1-10 \mathrm{~km}$ coverage capacity and height of $30 \mathrm{~m}$ or above is favorable for clear reception.

\subsection{Femtocells}

Compared with macrocells, femtocells are low power budget nodes that are mounted to enhance coverage in indoor and residential environments. Femtocells are deployed by customers with poor coverage or no coverage. They provide the user terminals with services like voice and data by connecting to the core network through a broadband internet connection like cable or digital subscriber line.

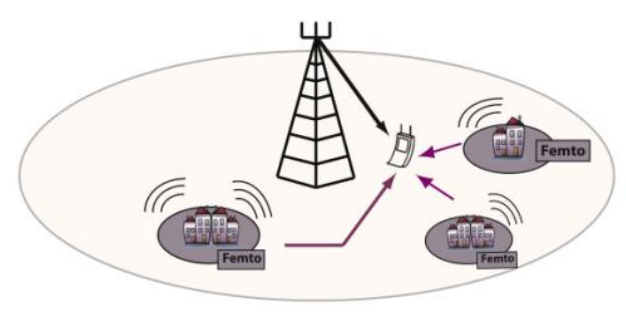

Fig 1: Heterogeneous Deployment [10]

\subsection{WIDEBAND CODE DIVISION MULTIPLE ACCESS (WCDMA)}

WCDMA is a $3 \mathrm{G}$ technology air interface that operates using code division multiplexing to provide customers with high bandwidth, multimedia support among others. WCDMA compared with the GSM system that operates using time division multiplexing spreads its transmission over a wide carrier $(5 \mathrm{MHz})$ and it can accommodate both voice and data service simultaneously. WCDMA can offer up to $2 \mathrm{Mbps}$ of downlink speed at peak network, it has a high throughput of between 220-320 Kbps for file downloads and data rate of 384 Kbps at peak network. All these features serve as a boast over other air interface like EDGE.

\section{SYSTEM MODEL}

The problem to be addressed is the deployment of low power nodes alongside with macrocell this is often believed to reduce the energy consumption of cellular networks [4]. The idea is based on WCDMA downlink load equation. The introduction of femtocells would reduce the macrocells density which will in turn reduce the energy consumed by the macrocell of the network. More specifically we assumed:

- No interference among users.

- Femtocells are turned on only when there is traffic.

- We also assumed that Macrocell Inter Site Distance (ISD) is fixed, but load is decreasing with additional femtocells.

- Femtocells are turned on only when there is traffic

For comparisons the software carries out dimensioning of the network with femtocells penetration at different percentage, also with femtocells of different power budgets ( $2 \mathrm{~W}$ and 5 W). The dimensioning was carried out with software developed with Microsoft Visual Studio 10 [11], a database was also created for the software using Microsoft Access 2010 [12] and the data obtained was displayed in graphic form. The software automatically calculates the total number of users in the cell area, the area site, range of the cell base on okumura- hata (urban area) and daily energy consumption per square kilometer.

\subsection{SOFTWARE ANALYSIS}

The software is classified into six modules. The six modules available are compute, refresh, femtocell power graph, $5 \mathrm{~W}$ femtocell power graph, $2 \mathrm{~W}$ femtocell power graph and plot combined graph.

- Compute module: This is the command that works out all the required operations based on the equations supplied by the program. The services provided by this module are as follows;

$\checkmark \quad$ Computes the Equivalent Isotropic Radiated Power (EIRP)

$\checkmark \quad$ Computes the Reciever Noise density

$\checkmark$ Computes the Receiver Noise power

$\checkmark$ Computes the Interference Margin

$\checkmark$ Computes the Reciever Interference power

$\checkmark$ Computes the Noise and Interference

$\checkmark$ Computes the Processing Gain

$\checkmark \quad$ Computes the Receiver Sensitivity

$\checkmark \quad$ Computes the Maximum and Average path losses

$\checkmark$ Computes the Cell Range base on Hata- Model

$\checkmark$ Computes the Total number of users in the cell

$\checkmark$ Computes the Daily energy consumption kWh

$\checkmark$ Computes the Amount of energy saved based on the femtocell power budget and ratio.

- Refresh module: This module that clears the screen of the application.

- Femtocell power graph module: This is the command that plots the graph based on the data obtained from the first module.

- 5 W Femtocell power graph module: This is the command that plots the graph based on the data obtained with a femtocell power budget of $5 \mathrm{~W}$.

- 2 W Femtocell power graph module: This is the command that plots the graph based on the data obtained with a femtocell power budget of $2 \mathrm{~W}$.

- Plot combined graph module: This is the command that plots it graph based on data obtained from the third, fourth and fifth.

\subsection{SOFTWARE DESIGN ANALYSIS}

This section outline the design of the most common objects, their basic identity and actions performed in the system.

\section{- Computes the Equivalent Isotropic Radiated} Power (EIRP)

This is the total amount of power that a functional isotopic antenna needs to radiate in order to achieve the required value. The EIRP can be calculated from the equation below.

$$
\operatorname{EIRP}(d B m)=P_{t}(d B m)+h_{f}(d B i)-L_{t}(d B)
$$

Where EIRP and $P T$ (output power of transmitter) are measured in $\mathrm{dBm}$, antenna gain $h_{f}$ is expressed in $\mathrm{dBi}$. and losses $L_{t}$ is in $\mathrm{dB}$.

\section{- Computes the Reciever Noise density}

It is the power spectral density of the noise [13]. The thermal noise density is given by $\mathrm{NO}=\mathrm{kT}$, where $\mathrm{k}$ is Boltzmann's 
constant measured in joules per Kelvin, and $\mathrm{T}$ denotes the receiver system noise temperature in Kelvin is given in $\mathrm{dBm} / \mathrm{Hz}$

\section{- Computes the Reciever Noise power}

This total noise per bandwidth unit at the input or output of a device when the signal is not present and can be calculated by the formular below:

$$
N p=N d+10 * \log (C R)
$$

Where $N p$ is the noise power, $C R$ is the value for the chip rate and $N d$ represents the noise density

\section{- Computes the Interference Margin}

This is the increase noise level caused by greater load in a cell.

$$
I M(d B)=-10 \log 10(1-\lambda)
$$

Where $I M$ is the interference margin and $\lambda$ is the load factor

\section{- Compute the Processing gain}

In a spread spectrum system, the process gain (or 'processing gain') is the ratio of the spread (or RF) bandwidth to the unspread (or baseband) bandwidth. It is usually expressed in decibels $(\mathrm{dB})$.

$$
P G=10 \log 10 \frac{S F}{\eta}
$$

Where $P G$ the processing gain, $S F$ is the spreading factor and $\eta$ is the bit rate

\section{- Computes the Receiver sensitivity}

The receiver sensitivity can be calculated from the formula below

$$
R x S=N_{i}-P G+E b / N o-h_{f}+\vartheta
$$

Where $R x S$ is the receiver sensitivity, $N i$ is the noise interference, $P G$ is the processing gain, $E b / N o$ the ratio of energy per bit to the spectral noise density, $h_{f}$ is the antenna gain and $\vartheta$ is the antenna loss.

\section{- Computes the Maximum and Average path} losses

This is the reduction in power density (attenuation) of an electromagnetic wave as it propagates through space. The path loss could be Maximum path loss or Average path loss which is usually about $6 \mathrm{~dB}$ less than maximum path loss.

$$
M p l=E I R P-R . S
$$

Where $M p l$ is the maximum path loss, EIRP is equivalent isotropically radiated power and $R . S$ is the receiver sensitivity.

$$
A p l=M p l-\kappa-\delta+\mu
$$

Where $\mathrm{Apl}$ is the average path loss, $\mathrm{Mpl}$ is the maximum path loss, $\kappa$ is the log normal fading, $\delta$ is the indoor penetration loss and $\mu$ is the soft handover gain.

- Computes the Cell range base on Hata- model In this work we adopted Okumura-Hata propagation model as it predits and provides a realiable path loss in Nigeria based on the analysis given in [14] [15] [16]. For an urban macrocell with base station receiver height of $30 \mathrm{~m}$, mobile equipment antenna height of $1.5 \mathrm{~m}$ and carrier frequency of $2000 \mathrm{MHz}$ [5].

$$
L(d b)=137.4+35.2 \log 10(R)
$$

Where $\mathrm{L}(\mathrm{db})$ is the path loss and $\mathrm{R}$ is the range in $\mathrm{km}$.

\section{POWER CONSTRAINT}

From the WCDMA downlink load equations [7]. This research work introduces modeling for performance comparisons and show how load equations can be utilized in this context. In the following we simplify the load equations by assuming that dimensioning is done based on a certain service. The load factor [7] can be calculate from Equation 9

$$
\lambda=\lambda o+\text { Nuser } * \frac{(E b / N o)^{*} R d^{*} V}{B W} *(1-\alpha+\imath)
$$

In equation (9) parameter $\lambda o$ refers to the minimum load, $N$ is the number of users in the cell, $E b / N o$ is the energy per users bit divided by the spectral density. $V$ is the connection activity factor, $B W$ is the system chip rate, $\alpha$ is the spreading code orthogonality factor and $l$ is the other-to-own cell interference factor. To calculate the total numbers of users can be obtained from equation (9). From the work in [4] the total power consumption of the mobile network over certain period of time can be expressed in the form

$$
\text { Pcell }=\text { Nbs } * \text { Pbs }+ \text { Nue } * \text { Pue }+ \text { Pother }
$$

Where $N b s, P b s$ refers to number of base stations and power consumed by single base station respectively. Nue, Pue defines the number of user equipment's and power consumed by single user equipment respectively and the last term contains power spent by other mobile network equipment's such as core network elements etc. The power spent by other mobile equipment's was not considered in this research.

$$
\text { Pcell }=P . O+\lambda * P . T
$$

From equation (11) power to transmit (P.T) is needed to create required transmission power in antenna output and $\lambda$ is the cell load that may vary between 0.1 and 0.9 depending on the users load and radio interface configuration. Power to operate (P.O) contains all load independent power that is needed to operate the base station.

$$
\text { Psite }=\text { Ncell } *(P . O+\lambda * P . T) * T
$$

Equation 12 defines the cell power while sites are usually composed by three or more sectors that each forms a logical cell. Where Ncell is the number of cells in the site. The site energy consumption over a time period $T$ is could be obtained from equation below

$$
\text { Esite }=\text { Ncell } *(P . O+\lambda * P . T) * T
$$

When heterogeneous networks are deployed, the daily energy utilized by the network is given by

$$
(E / A) n t w=N c e l l * \frac{(P . O+\lambda n e w * P . T)}{\text { Asite }} * 24 h
$$

In order to make our calculation more accurate this research considered [4] the UTMS macro base station specification value $P . O=137 \mathrm{~W}$ and $P . T=57 \mathrm{~W}$ which will be then used in calculation and P.F is the power of femtocell.

$$
(E / A) n t w=N c e l l * \frac{(P . O+\lambda n e w * P . T+N f * P . F)}{\text { Asite }} * 24 h
$$

The model for calculating the energy consumed can be more easily understood through the flow chart in Fig. 1 


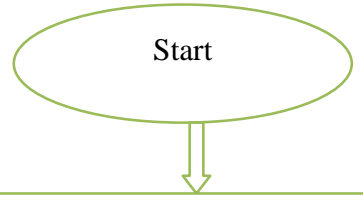

Input Required Link Budget Parameters

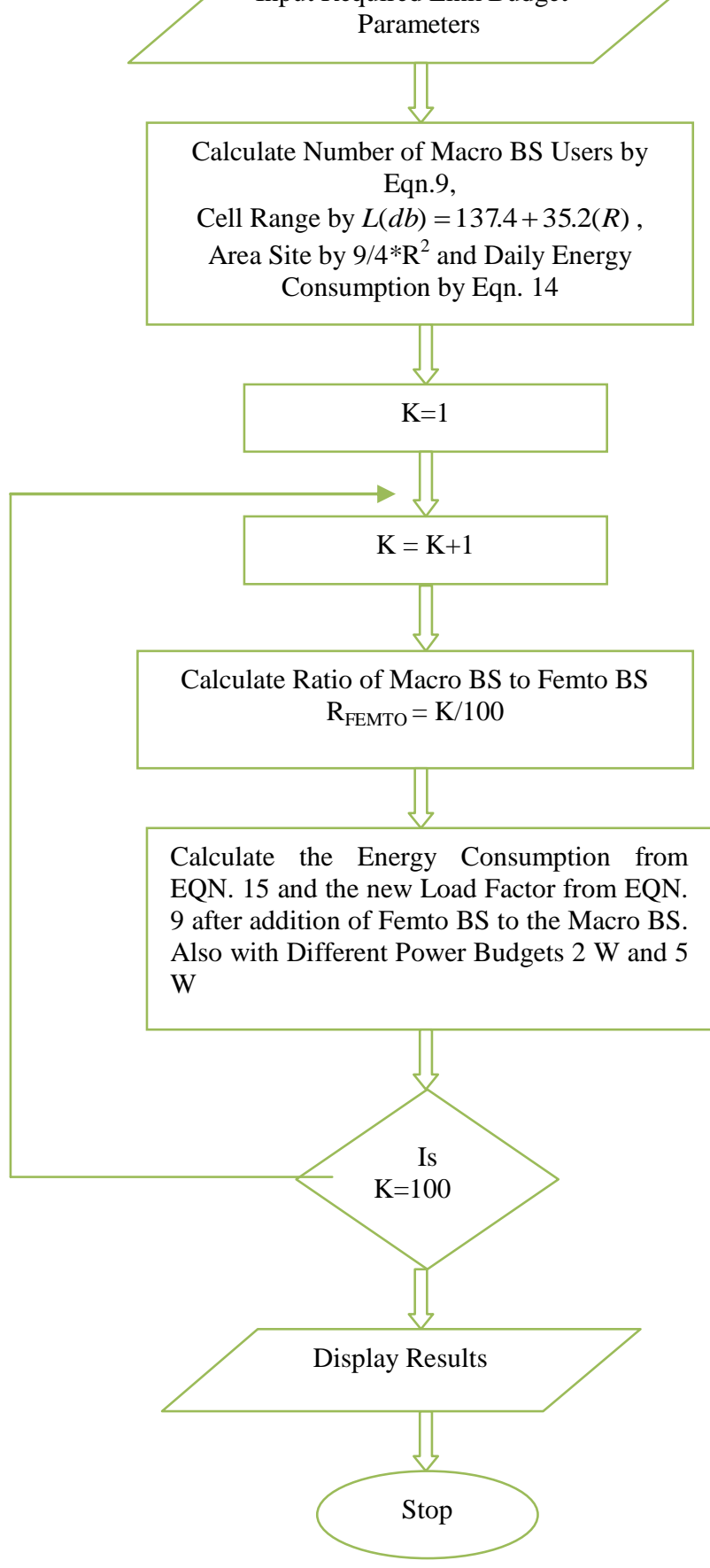

Fig 2: Flow chart for the energy consumption model

\section{NUMERICAL EXAMPLE}

We consider a WCDMA related example where parameter are given in Table 1

Table 1. UTMS Link Budget

\begin{tabular}{|c|c|}
\hline PARAMETER & VALUE \\
\hline Operating frequency & $2000 \mathrm{MHz}$ \\
\hline BS antenna height & $30 \mathrm{~m}$ \\
\hline MS antenna height & $1.5 \mathrm{~m}$ \\
\hline Propagation model & Okumura-Hata (urban area) \\
\hline BS transmission power (dBm) & $43 \mathrm{dBm}(20 \mathrm{w})$ \\
\hline Femtocell input power & $2 \mathrm{~W}, 5 \mathrm{~W}$ \\
\hline Bit rate & $64 \mathrm{kbps}$ \\
\hline $\begin{array}{c}\text { BS antenna gain including } \\
\text { losses }\end{array}$ & $16 \mathrm{dBi}$ \\
\hline System chip rate W & $3.84 \mathrm{Mcps}$ \\
\hline Shadow fading margin & $7 \mathrm{~dB}$ \\
\hline Orthogonality factor $\alpha$ & 0.50 \\
\hline Other to own cell I & 0.65 \\
\hline Activity factor & 1.0 \\
\hline Minimum load & 1.0 \\
\hline Indoor penetration loss & $10 \mathrm{~dB}$ \\
\hline Load factor & 0.75 \\
\hline Cable and connector losses \\
(dB) & 3 \\
\hline Soft handover gain & $2 \mathrm{~dB}$ \\
\hline Antenna gain Rx & $2 \mathrm{dBi}$ \\
\hline Noise figure & 7 \\
\hline Eb/No & $5 \mathrm{~dB}$ \\
\hline
\end{tabular}

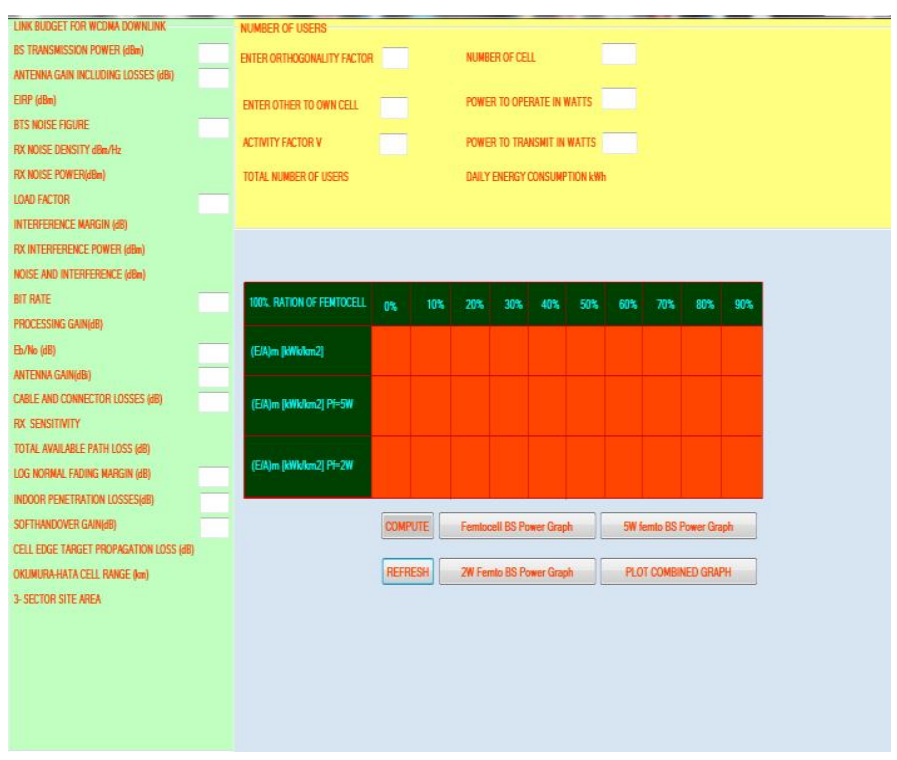

Fig 3: Interface of the energy efficient software

\section{NUMERICAL RESULTS}

Base on the value obtained from the second row in table 2 it was observed in figure 4 that energy consumption per square kilometer is clearly reducing in macrocell when ratio of femtocells connection is increasing. 
Table 2. Increment in femtocells in the network

\begin{tabular}{|c|c|c|c|c|c|c|c|c|c|}
\hline $\begin{array}{c}\mathbf{1 0 0} \% \mathbf{R} \\
\text { femto }\end{array}$ & $10 \%$ & $20 \%$ & $30 \%$ & $40 \%$ & $50 \%$ & $60 \%$ & $70 \%$ & $80 \%$ & $90 \%$ \\
\hline $\begin{array}{c}\text { (E/A)m } \\
\mathbf{K w m} / \mathbf{K m}^{2}\end{array}$ & 23.24 & 22.75 & 22.26 & 21.77 & 21.28 & 20.79 & 20.30 & 19.81 & 19.32 \\
\hline
\end{tabular}

Fig. 4 shows the daily energy consumption per squre kilometer. It can be observed that the energy consumption by the microcell decrease with increase in the ration of femtocell cells in the network.

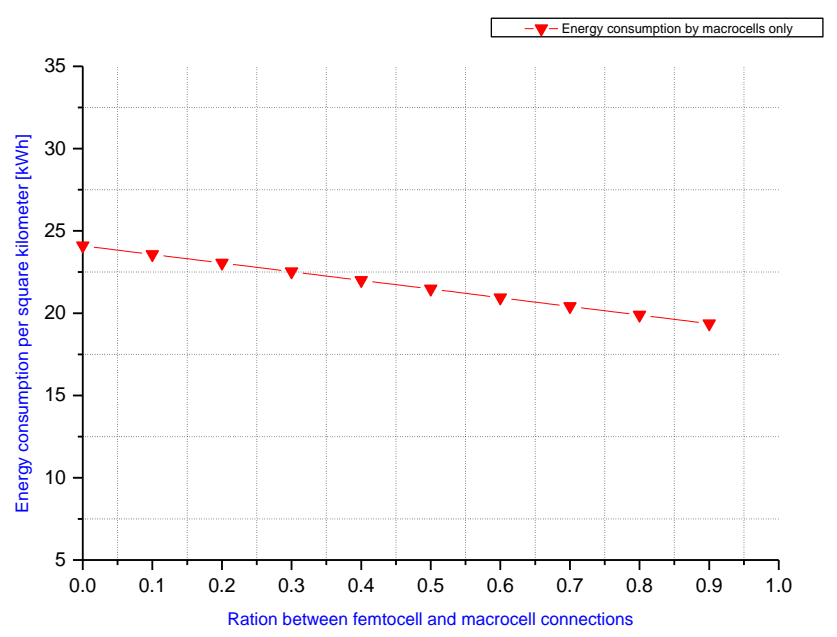

Fig 4: Daily energy consumption per square kilometer in the network when introducing femtocell into the network.

From fig. 4, when no femtocell is introduced on the network, the energy consumption is about $24.0 \mathrm{kwm} / \mathrm{km}^{2}$, this decreases to about $21.28 \mathrm{kwm} / \mathrm{km}^{2}$ and $19.32 \mathrm{kwm} / \mathrm{km}^{2}$ when $50 \%$ and $90 \%$ of femtocells are deployed respectively. However, the introduction of femtocells to the network ordinarily does not gauratiy decerease in power consumption. The scenario depends on the power budget of the femtocell as shown in figure 5 and 6

Table 3. Show the result of increment in femtocells with power budget of $5 \mathrm{~W}$ in the network

\begin{tabular}{|c|c|c|c|c|c|c|c|c|c|}
\hline $\begin{array}{l}\mathbf{1 0 0 \%} \\
\text { femto }\end{array}$ & $10 \%$ & $20 \%$ & $30 \%$ & $40 \%$ & $50 \%$ & $60 \%$ & $70 \%$ & $80 \%$ & $90 \%$ \\
\hline $\begin{array}{c}(\mathbf{E} / \mathbf{A}) \mathbf{m} \\
\mathbf{k w m} / \mathbf{k m}^{2}\end{array}$ & 24.38 & 24.65 & 24.93 & 25.21 & 25.49 & 25.79 & 26.04 & 26.32 & 26.59 \\
\hline
\end{tabular}

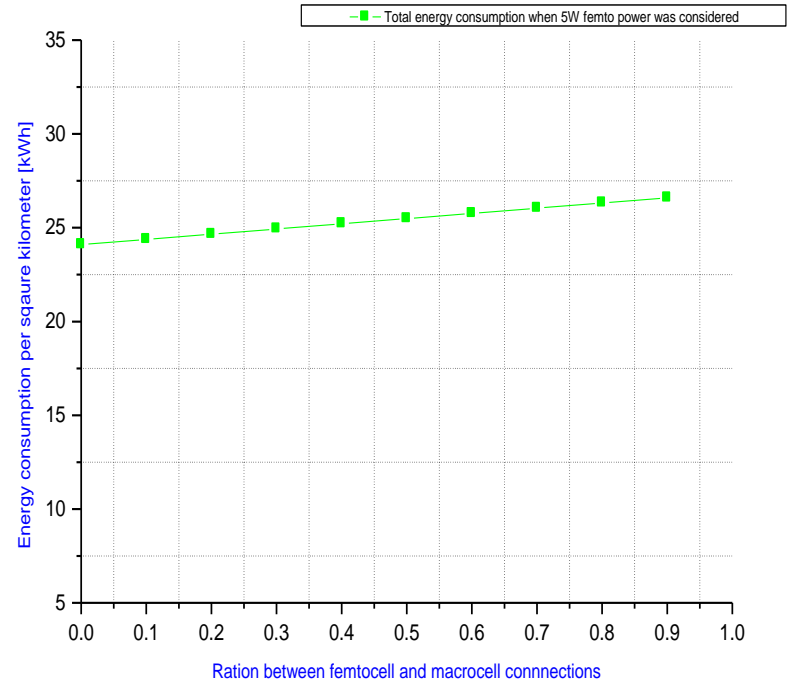

Fig 5: Total energy consumption with $5 \mathrm{~W}$ femtocell

In table 3 and figure 5 if femtocells with power budget $5 \mathrm{~W}$, is introduced to the network then the total energy consumption in the network increases since load decay in macrocell load cannot compensate the increase consumption due to femtocells.

Table 4. Show the result of increment in femtocells with power budget of $2 \mathrm{~W}$ in the network.

\begin{tabular}{|c|c|c|c|c|c|c|c|c|c|}
\hline $\begin{array}{c}\mathbf{1 0 0} \% \mathbf{R} \\
\text { femto }\end{array}$ & $10 \%$ & $20 \%$ & $30 \%$ & $40 \%$ & $50 \%$ & $60 \%$ & $70 \%$ & $80 \%$ & $90 \%$ \\
\hline $\begin{array}{c}\text { (E/A)m } \\
\mathbf{k w m} / \mathbf{k m}^{2}\end{array}$ & 23.90 & 23.69 & 23.49 & 23.28 & 23.08 & 22.87 & 22.66 & 22.46 & 22.25 \\
\hline
\end{tabular}

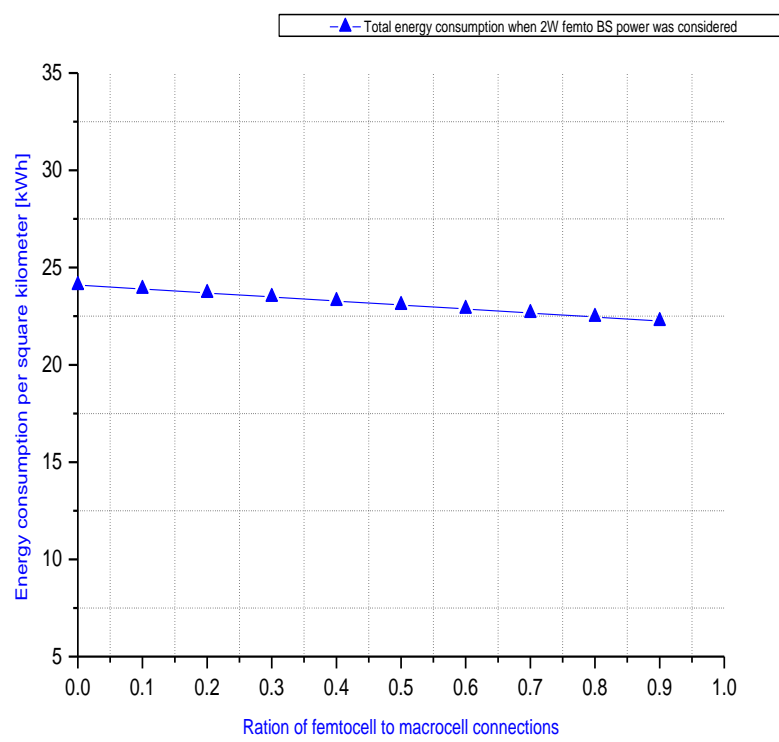

Fig 6: Total energy consumption with $2 \mathrm{~W}$ femtocell 


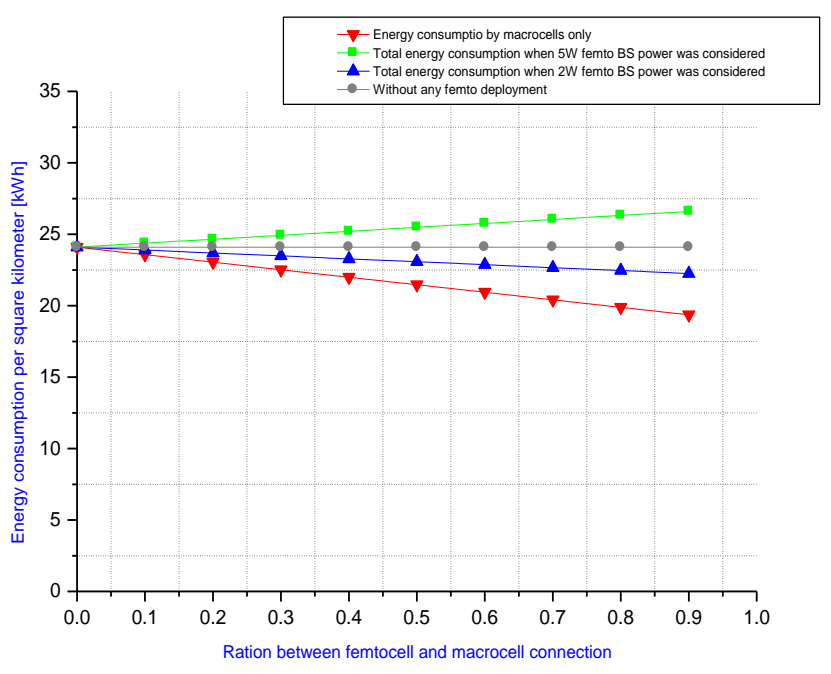

Fig 7: Daily energy consumption per square kilometer in the network when assuming energy consumption by macrocell only, total energy consumption with $5 \mathrm{~W}$ femtocells power and total energy consumption with $2 \mathrm{~W}$ femtocells power

From fig. 7 we observed that in case of $40 \%$ femtocells with 2 $\mathrm{W}$ power budget deployment in macrocell, around $4 \%$ of the energy would be save and it keeps on increasing as femtocells deployment increases. Where as in case of $10 \%$ femtocells with $5 \mathrm{~W}$ power budget, then the total energy consumption in the network is growing since the load decay in macrocell cannot compensate the additional consumption due to femtocells.

\section{CONCLUSION}

This paper focused on the WCDMA energy saving through femtocells deployment. A simple model for the energy consumption per unit area has been derived based on WCDMA downlink load equations. Based on the model, three different deployment scenarios have been compared to make the conclusion from energy consumption perspective. In conclusion, the significance of femtocells to the energy efficiency of the WCDMA network has been studied under the consideration of a valuable power save feature of femtocell.

\section{REFERENCES}

[1] Malmodin J, Moberg A, Lunden D, Finnveden G and L"ovehagen N, 2010 "Greenhouse Gas Emissions and Operational Electricity Use in the ICT and Entertainment \& Media Sectors" Journal of Industrial Ecology, vol. 14 issue 5, pp. 770-790, October 2010.

[2] Pickavet M, Vereecken W, Demeyer S, Audenaert P, Vermeulen B, Develder D, Colle B, Dhoedt B and Demeester P, 2008, "Worldwide energy needs for ICT: The rise of power-aware networking" 2nd International Symposium on Advanced Networks and Telecommunication Systems (ANTS 2008), pp. 1-3, December 2008.

[3] Cisco Visual Networking Index : Global Mobile Data Traffic Forecast Update 2010 - 2015”. Tech.rep, Cisco Febuary 2011.

[4] Maliha Urooj Jada, 2011, "Energy efficiency techniques \& challenges for mobile access networks," Master's
Thesis submitted in partial fulfillment of the degree of Master of Science Espoo, May, 2011.

[5] Faruk N, Ayeni A.A, Muhammed M.Y, Abdulkarim A and Moses O, 2012 "Hybrid power systems for cell sites in mobile cellular networks" journal of selected areas in renewable and sustainable energy (JRSE). Cyber multidisciplinary journals, Canada. Vol. 3, No. 1, pp 812, 2012.

[6] Faruk N, Ayeni A.A, Muhammed M.Y, Abdulkarim A and Moses O, 2013 “ Techniques for minimizaing power consumption of base transceivers station in mobile cellular systems" international journal of sustainability (IJS) Vol. 2, No.1, 2013.

[7] Holma, H and Toskala A, 2004, “WCDMA for UTMS," Third Edition, John Wiley \& Sons, pp. 99-148.

[8] Broadband Planner available http://rsl.ece.ubc.ca/planning.html Visited on 29/1/2013

[9] Radio Network Planning and Optimization Software available at http://www.akosim.com ${ }^{-}$Visited on 29/1/2013.

[10] Heterogeneous networks available at http://www.profheath.org/research/heterogenousnetworks/femtocells/ visited on 2/2/2013.

[11] http://msdn.microsoft.com/enus/library/dd831853(v=vs.100).aspx visited on 3/7/2013.

[12] http://office.microsoft.com/en-us/support/getting-startedwith-office-2010-FX101822272.aspx visited on 3/7/2013.

[13] Noise density available at http://en.wikipedia.org/wiki/ noice density visited on 15/1/20134

[14] Faruk N, Ayeni A.A and Adediran Y.A, 2013 "Impact of path loss models on spatial tv white space" European scientific journal, vol. 4, pp.543-547,2013.

[15] Faruk N, Adediran Y.A and Ayeni A.A, 2013 “ on the study of empirical path loss models for accurate prediction of tv signal for secondary users" progress in electromagnetic research (PIER) B, USA, Vol. 49, pp.155-176, 2013.

[16] Faruk N, Ayeni A.A and Adediran Y.A, 2013 “ error bounds of empirical path loss models at vhf/uhf bands in kwara state, Nigeria" in proc. IEEE Region 8, EUROCON Conference, Croatia July $1^{\text {st }}-4^{\text {th }}, 2013$ pp.602-607

[17] 3GPP: LTE: 3rd Generation Partnership Project: Technical Specification Group Radio Access Network: Evolved Universal Terrestrial Radio Access (E-UTRA): User Equipment (UE) radio transmission and reception (TS 36.101 v9.1.0 Release 9) 2009.

[18] Louhi J. T., 2007, "Energy efficiency of modern cellular base stations" in Proc. of $29^{\text {th }}$ Internet telecommunication energy conference (INTELEC 2007), Rome,Italy, pp. 475-476, September,2007.

[19] Zhou S, Gong J, Yang Z, Niu Z, Yang P, 2009,“Green Mobile Access Network with Dynamic Base Station Energy Saving”. MobiCom'09, Beijing, China, Sept 2009. 
[20] Correia L, Zeller D, Blume O, Ferling D, Jading Y, Godor I, Auer G, Van Der Perre L, 2010, "Challenges and enabling technologies for energy aware mobile radio networks" Communications Magazine, IEEE, vol.48 no. 11 pp. $66-72,2010$.

[21] Ashraf I, Ho L. T. W, and Claussen H, 2010,"Improving energy efficiency of femtocell base stations via user activity detection” in Proc. of IEEE WCNC'2010, 2010.

[22] Faruk N, Ayeni A.A, Muhammad M. Y, Olawoyin L.A, Abdulkarim A, Agbakoba J, Moses O, 2012 " Techniques For Minimizing Power Consumption Of Base Transceivers Station in Mobile Cellular Systems" Accepted for Publication March 2012, International Journal of Engineering and Technology, IJET UK Publication
[23] 4x4 communication UHF CB Radio available at http://goc.gracecre.org.au/index.php?option $=$ com content\&itemid $=6$ visited on 22/1/2013.

[24] Jada M, Hämäläinen J, Jäntti R, Hossain M. M. A, 2010, "Impact of Femtocells to the WCDMA Network Energy Efficiency". IEEE IC-BNMT, China, October 2010.

[25] Faruk N, Muhammad M. Y, Bello O. W, Abdulkarim A, John A and Gumel M, 2012, " Energy Conservation Through Site Optimization For Mobile Cellular Systems" Epistemic in Science, Engineering and Technology (ESET) Canada, 2012, Vol 2, No 1, 2012, Page 26-33

[26] Faruk N and Gume M.I, 2011, “3G Network Initial Pilot Coverage Design and Optimization," book published by LAP Lambert Academic Publishing GmBH \& Co. KG, Germany, 2011, ISBN 978-3-84439789-1 